\title{
Evaluating performance of health care facilities at meeting HIV-indicator reporting requirements in Kenya: an application of K-means clustering algorithm
}

\author{
Milka Bochere Gesicho ${ }^{1,4^{*}}$ (D), Martin Chieng Were ${ }^{2,4}$ and Ankica Babic ${ }^{1,3}$
}

\begin{abstract}
Background: The ability to report complete, accurate and timely data by HIV care providers and other entities is a key aspect in monitoring trends in HIV prevention, treatment and care, hence contributing to its eradication. In many low-middle-income-countries (LMICS), aggregate HIV data reporting is done through the District Health Information Software 2 (DHIS2). Nevertheless, despite a long-standing requirement to report HIV-indicator data to DHIS2 in LMICs, few rigorous evaluations exist to evaluate adequacy of health facility reporting at meeting completeness and timeliness requirements over time. The aim of this study is to conduct a comprehensive assessment of the reporting status for HIV-indicators, from the time of DHIS2 implementation, using Kenya as a case study.
\end{abstract}

Methods: A retrospective observational study was conducted to assess reporting performance of health facilities providing any of the HIV services in all 47 counties in Kenya between 2011 and 2018. Using data extracted from DHIS2, K-means clustering algorithm was used to identify homogeneous groups of health facilities based on their performance in meeting timeliness and completeness facility reporting requirements for each of the six programmatic areas. Average silhouette coefficient was used in measuring the quality of the selected clusters.

Results: Based on percentage average facility reporting completeness and timeliness, four homogeneous groups of facilities were identified namely: best performers, average performers, poor performers and outlier performers. Apart from blood safety reports, a distinct pattern was observed in five of the remaining reports, with the proportion of best performing facilities increasing and the proportion of poor performing facilities decreasing over time. However, between 2016 and 2018, the proportion of best performers declined in some of the programmatic areas. Over the study period, no distinct pattern or trend in proportion changes was observed among facilities in the average and outlier groups.

Conclusions: The identified clusters revealed general improvements in reporting performance in the various reporting areas over time, but with noticeable decrease in some areas between 2016 and 2018. This signifies the need for continuous performance monitoring with possible integration of machine learning and visualization approaches into national HIV reporting systems.

Keywords: K-means clustering, Completeness, Timeliness, Performance, DHIS2

*Correspondence: milcagesicho@gmail.com

1 Department of Information Science and Media Studies, University

of Bergen, Bergen, Norway

Full list of author information is available at the end of the article

\section{Background}

The Human Immunodeficiency Virus (HIV) epidemic remains a challenge globally with highest infected numbers found in countries in East and Southern Africa, 
which accounted for an estimated 20.7 million infected individuals in 2019 [1]. Efforts to eradicate the HIV epidemic have seen affected countries in low-middleincome-countries (LMICs) receive substantial support from donors and multilateral global organizations in order to scale-up HIV services such as antiretroviral therapy (ART), prevention of mother-to-child transmission (PMTCT) of HIV, and HIV testing and counselling (HTC) [2]. This has brought about the need to strengthen strategic information on HIV. Health Management Information Systems (HMIS), through better data quality, improves decision-making such as informing policy, measuring program effectiveness, advocacy and resource allocation [3]. Ministries of Health $(\mathrm{MoH})$ and donor organizations require facilities providing HIV services to report several aggregated HIV-indicators as part of Monitoring and Evaluation (M\&E) program $[4,5]$.

The scale-up of HIV services has contributed to strengthening of HMIS in many low-middle-incomecountries, resulting in improved availability of routinely generated HIV aggregate indicator data from health facilities to the national level [6]. HIV indicator data typically comes from aggregation of monthly reports generated by various facilities that are collated in summary forms and submitted to an aggregate-level HMIS or reporting system [6]. One such national-level data aggregation system is the District Health Information Software Version 2 (DHIS2), which has been adopted by many LMICs [7].

Aggregate data stored in systems such as DHIS2 are only as good as their quality [8]. Therefore, the ability to report complete, accurate and timely data by HIV care providers and other entities is a key aspect in monitoring trends in HIV care. Various approaches to evaluating data quality have been proposed such as desk reviews, data verification or system assessments across the following data quality dimensions; completeness, timeliness, internal consistency of reported data, external comparisons and external consistency of population data [9]. Evaluations on quality of indicator reporting leveraging some of these approaches have previously been conducted within DHIS2 based on various data quality dimensions [1014].Nonetheless, despite a long-standing requirement to report HIV indicator data to DHIS2 in LMICs, few rigorous evaluations exist to evaluate adequacy of health facility reporting at meeting completeness and timeliness requirements over time.

Rigorous reporting by facilities into DHIS2 over time is imperative to identify changes in trends and implement timely interventions [14]. In this study, we aim to leverage on machine learning algorithms as well as data visualization approaches to conduct a comprehensive assessment of the reporting performance for HIV-indicators at the national-level by facilities using completeness and timeliness indicators, with Kenya as a case study.

\section{Methods \\ Related works}

Table 1 illustrates some of the related studies that have extracted data from DHIS2 in order to evaluate performance at meeting the various dimensions of data quality. In addition, data from these studies was gathered from various time periods as well as various areas within health care such as malaria.

Whereas our study focused on facility reporting completeness and timeliness of HIV-indicators for the period of 2011 to 2018, the difference compared with the other studies is leveraging of the k-means clustering algorithm.

Table 1 Summary of some of the related works evaluating various dimensions of data quality

\begin{tabular}{|c|c|c|c|c|c|c|}
\hline \multirow[t]{2}{*}{ Studies } & \multicolumn{6}{|c|}{ Dimensions evaluated } \\
\hline & $\begin{array}{l}\text { Facility } \\
\text { reporting } \\
\text { completeness }\end{array}$ & $\begin{array}{l}\text { Indicator data } \\
\text { completeness }\end{array}$ & Timeliness & $\begin{array}{l}\text { Internal } \\
\text { consistency }\end{array}$ & $\begin{array}{l}\text { External } \\
\text { consistency }\end{array}$ & Summary \\
\hline Bhattacharya et al. [10] & $x$ & $x$ & $x$ & $x$ & $x$ & $\begin{array}{l}\text { Extracted priority maternal and neonatal health } \\
\text { indicators } \\
\text { Data gathered from July } 2016 \text { to June } 2017\end{array}$ \\
\hline Githinji et al. [11] & $x$ & $x$ & - & - & - & $\begin{array}{l}\text { Extracted malaria indicator data } \\
\text { Data gathered from 2011-2015 }\end{array}$ \\
\hline Adokiya et al. [12] & $x$ & - & $x$ & - & - & $\begin{array}{l}\text { Extracted disease surveillance and response } \\
\text { reports } \\
\text { Data gathered from } 2012 \text { and } 2013\end{array}$ \\
\hline Nisingizwe et al. [14] & $x$ & $x$ & - & $x$ & - & $\begin{array}{l}\text { Extracted health management information } \\
\text { systems data for selected indicators } \\
\text { Data gathered from 2008-2012 }\end{array}$ \\
\hline Kiberu et al. [13] & $x$ & - & $x$ & - & & $\begin{array}{l}\text { Extracted inpatient and outpatient data } \\
\text { Data gathered from 2011/12 and after 2012/13 }\end{array}$ \\
\hline
\end{tabular}




\section{Study setting}

This study was conducted in Kenya, a sub-Saharan country made up of 47 counties. Administratively, the health care service delivery system has six levels, namely: community, dispensary, health center, district hospital, provincial hospital, and national referral hospital [15]. Kenya adopted the DHIS2 in 2011 at the national level for aggregation of health data across different levels of the health system $[16,17]$.

\section{Study design}

A retrospective observational study was conducted in order to identify reporting performance over time by health facilities in meeting completeness and timeliness reporting requirements.

\section{Data source}

Data for facilities reporting completeness and timeliness between the years 2011 and 2018 were extracted from the DHIS2 in Kenya. DHIS2 is a web-based opensource health management information system developed for purposes of collecting aggregate level data routinely generated across health facilities in various countries $[7,16]$. DHIS2 also supports various activities and contains modules for processes such as data management and analytics, which contain features for data visualization, charts, pivot tables and dashboards [18]. It is also currently in use by ministries of health in over 70 countries [19]. In Kenya, DHIS2 was rolled out nationally in the year 2011 [16]. Reporting completeness and timeless data were extracted from Kenya's DHIS2 for all facilities in all the 47 counties in Kenya. Systematic procedures were used in cleaning the data using a generic five-step approach as outlined in Gesicho et al. [20]. Data used were only for facilities that offered one or more of the outlined HIV services that required reporting, namely: (1) HIV testing and counselling (HTC), (2) Prevention of Mother to Child Transmission (PMTCT), (3) Care and Treatment (CRT), (4) Voluntary Medical Male Circumcision (VMMC), (5) Post-Exposure Prophylaxis (PEP) and (6) Blood Safety (BS). These data were derived based on the $\mathrm{MOH} 731$ Comprehensive HIV/AIDS facility-reporting form, which is the major monthly HIV summary report required by the $\mathrm{MOH}$ in Kenya and used by health facilities for reporting of HIV-indicators into DHIS2. It is worth noting that health facilities are not required to report on indicators for all the six programmatic areas, but only those for which they provide services. As such, there are variations in number of facilities ( $n$ ) in the various programmatic reporting areas.

\section{Measures}

Facility reporting completeness and timeliness

Percentage completeness in facility reporting is calculated automatically within Kenya's DHIS2 and is defined as the number of actual monthly reports received divided by the expected number of reports in a given year. Percentage timeliness in facility reporting is also calculated automatically within Kenya's DHIS2 and is defined as the number of actual monthly reports received on time (by the 15th of every month) divided by the expected number of reports in a given year. Facility reporting completeness and timeliness were selected as indicators for assessing reporting performance as they were readily available within DHIS2 for the eight year period covered by the study.

\section{Outcome measures}

The primary outcome of interest consisted of identifying the performance in reporting by health facilities over time (2011-2018), with facilities put into various performance clusters and performance evaluated in the various programmatic areas.

\section{Data analysis}

K-means algorithm was preferred due to its efficiency and suitability in pattern recognition, its simplicity, ease of implementation as well as its empirical success [21]. K-means algorithm is a non-hierarchical procedure where $k$ represents the number of clusters, which need to be specified prior to any clustering [22]. Given that K-means algorithm uses unsupervised learning, the idea was to group the health facilities into $k$ homogeneous groups based on their performance in completeness and timeliness, in each of the six programmatic areas for each of the study years. Based on the data set and purpose of this study, we used the average silhouette coefficient, which is an intrinsic method of measuring the quality of a cluster [23]. The average value of the silhouette coefficient ranges between -1 (least preferable value indicating poor structure) and +1 (most preferable value indicating good structure). According to Kaufman and Rousseeuw, average silhouette measure that is greater than +0.5 indicates reasonable partitioning of data, whereas greater than +0.7 indicates a strong partitioning [24]. On the other hand average silhouette measures lower than +0.5 indicate a weak or artificial partitioning, whereas below +0.2 indicates no clusters can be exhibited from the data [24].

In order to determine the number of clusters $(k)$ to be generated, the Euclidean distance measure was applied and $k$ was specified within a set of values $[21,25]$. The 
range of $k$ values was then iteratively re-run with two values of $\mathrm{k}(\mathrm{k}=3$ and $\mathrm{k}=4)$ and inspecting the average corresponding silhouette values [26].

The proportion of facilities in the various cluster groups was then determined by calculating the percentage number of facilities in a particular cluster group out of the total facilities in that particular year. To illustrate the average performance of facilities within the various cluster groups, we developed a scatter chart visualization using Tableau [27]. In addition, HTC programmatic area was used as an illustrative example for the visualization, given that it is one of the most reported programmatic areas. Figures and tables were developed using Microsoft Word and Excel (Microsoft Office Version 18.2008.12711.0). All analyses were performed using SPSS [28]. A summary of the methods is illustrated in Fig. 1.

\section{Results}

Results from the silhouette coefficient average measures for each reporting area are presented in Table 2. The results ascertain that the average silhouette values for both $\mathrm{k}=3$ and $\mathrm{k}=4$ produce reasonable to strong partitioning except for 2011 under CRT where the values for $\mathrm{k}=3$ where below 0.5 , hence $\mathrm{k}=4$ was used in this case. Therefore, based on method criteria and interpretability of the data set, either $k=3$ and $k=4$ were used where reasonable to strong partitions were identified in the average silhouette measures. As such, $\mathrm{k}=4$ was used when more variation could be provided in the data from four clusters, and $k=3$ was used when three clusters provided more variation than four clusters. For VMMC and PEP programmatic areas, the number of health facilities was not enough to conduct cluster analysis in the year 2011.

The four clusters were characterized based on health facility performance as follows:

Best performers This cluster consisted of health facilities that had the highest percentage in reporting completeness and timeliness in a particular reporting year.

Average performers This cluster consisted of health facilities that had lower percentage in reporting completeness and timeliness compared to best performers in a particular year.

Poor performers This cluster consisted of health facilities with lowest percentage in reporting completeness and timeliness in a particular year.

Outlier performers This cluster consisted of health facilities with high percentage in completeness compared to average performers, but with low percentage in timeliness in that particular year.
Performance was therefore categorized per year by cluster. As such, the average percentage reporting completeness and timeliness for a particular cluster group may vary by year. It is worth noting that there were no clusters with low completeness and high timeliness as reports cannot be on time if they were not submitted in the first place. Detailed results by cluster for each reporting programmatic area are outlined below.

In Table 3 and Fig. 2, we present the segmentation of facilities based on performance cluster groups according to the HTC programmatic area. As such, Table 3 includes the average percentage for facility reporting completeness and timeliness for each cluster group in HTC for the number of facilities (n) in a particular year.

Figure 2 consists of a graphical presentation of the proportion of facilities in each cluster group per year for HTC. Based on performance trends presented in Fig. 2, the proportion of best performing facilities accounted for $72.55 \%$ in 2016 , which was a progressive increase from $31.50 \%$ in 2012. Nonetheless, in 2017 and 2018 the proportion of best performing facilities accounted for $58.30 \%$ and $51.08 \%$ respectively, which was a progressive decrease from $72.55 \%$ in 2016 . On the other hand, the proportion of poor performing facilities accounted for $3.40 \%$ in 2016, which was a progressive decrease from $74.93 \%$ in 2011 . However, the proportion of poor performing facilities accounted for $13.49 \%$ in 2018 , which was a progressive increase from $3.40 \%$ in 2016.

The proportion of average and outlier performing facilities varied in the different years with no steady trend. Nonetheless, in the latter years, the proportion of average performing facilities accounted for $20.02 \%$ in 2018, which was a progressive increase from $6.00 \%$ in 2016 . On the other hand, proportion of outlier performers accounted for $15.40 \%$ in 2018 , which was a decrease from $18.02 \%$ in 2017.

In Table 4 and Fig. 3, we present the segmentation of facilities based on performance cluster groups according to the PMTCT programmatic area. As such, Table 4 includes the average percentage for facility reporting completeness and timeliness for each cluster group in PMTCT for the number of facilities (n) in a particular year.

Figure 3 consists of a graphical presentation of the proportion of facilities in each cluster group per year for PMTCT. Based on performance trends presented in Fig. 3, the proportion of best performing facilities accounted for $74.01 \%$ in 2015 , which was a progressive increase from $18.80 \%$ in 2011 . Nonetheless, in 2018 the proportion of best performing facilities accounted for $47.15 \%$, which was a progressive decrease from $74.01 \%$ in 2015. On the other hand, the proportion of poor 


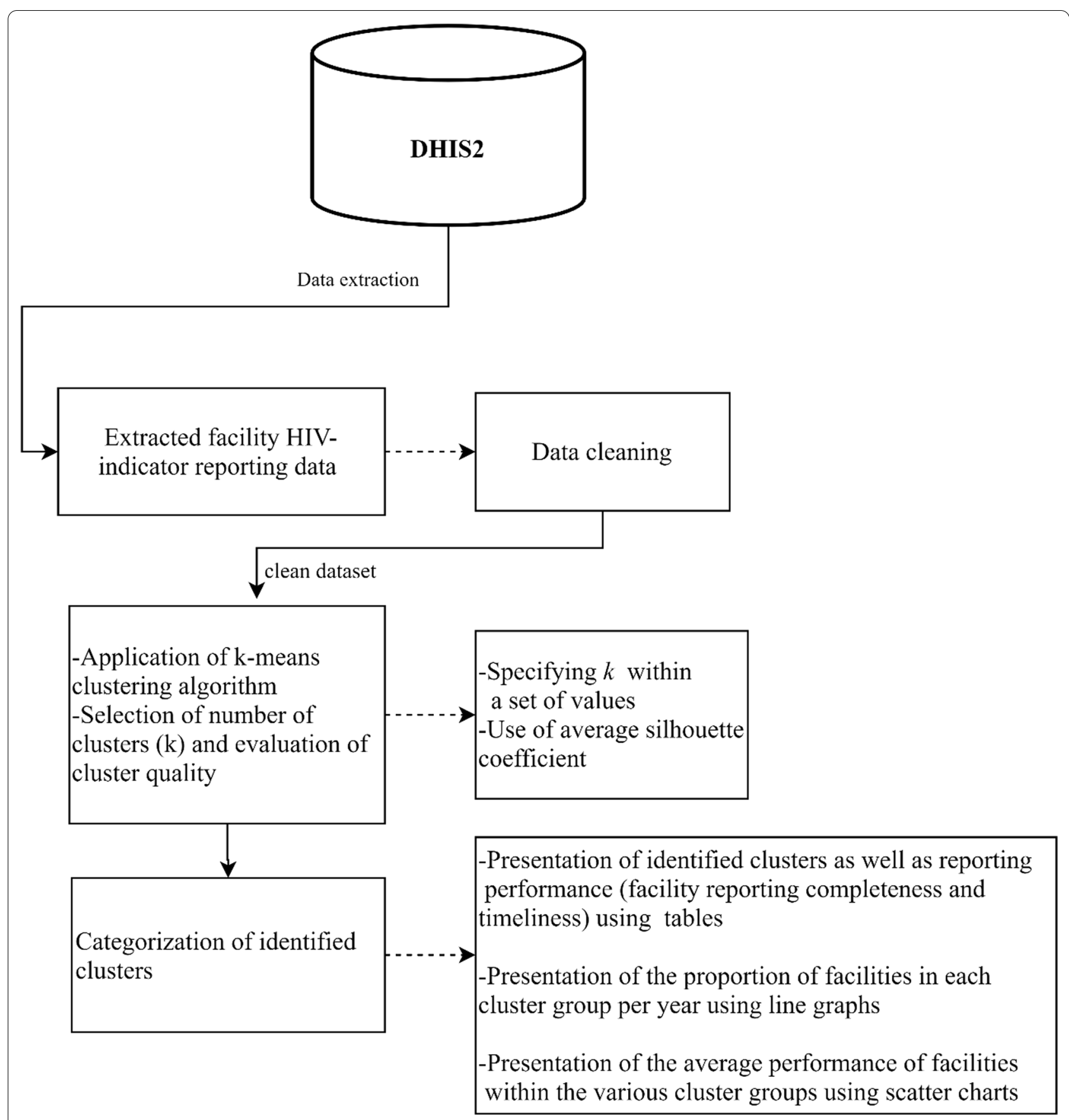

Fig. 1 Summary of methods

performing facilities accounted for $3.66 \%$ in 2015 , which was a progressive decrease from $77.07 \%$ in 2011 . However, in 2018 the proportion of poor performing facilities accounted for $14.61 \%$, which was a progressive increase from $3.66 \%$ in 2015.

The proportion of average and outlier performing facilities varied in the different years with no steady trend.
Nonetheless, for the latter years, proportion of average performing facilities accounted for $20.34 \%$ in 2018, which was an increase from $17.19 \%$ in 2017 . On the other hand, proportion of outlier performers accounted for $17.90 \%$ in 2018, which was an increase from 3.65\% in 2016.

In Table 5 and Fig. 4, we present the segmentation of facilities based on performance cluster groups according 
Table 2 Average of the Silhouette of a k-means clustering when $k=3$ and $k=4$

\begin{tabular}{|c|c|c|c|c|c|c|c|c|}
\hline \multicolumn{9}{|c|}{ Average silhouette measures } \\
\hline \multicolumn{3}{|l|}{ HTC } & \multicolumn{3}{|c|}{ РMTCT } & \multicolumn{3}{|l|}{ CRT } \\
\hline Year & $K=3$ & $\mathrm{~K}=4$ & Year & $\mathrm{K}=3$ & $\mathrm{~K}=4$ & Year & $K=3$ & $\mathrm{~K}=4$ \\
\hline 2011 & 0.800 & 0.775 & 2011 & 0.674 & 0.706 & 2011 & 0.368 & 0.582 \\
\hline 2012 & 0.526 & 0.563 & 2012 & 0.585 & 0.588 & 2012 & 0.556 & 0.599 \\
\hline 2013 & 0.659 & 0.648 & 2013 & 0.654 & 0.632 & 2013 & 0.637 & 0.618 \\
\hline 2014 & 0.669 & 0.669 & 2014 & 0.676 & 0.666 & 2014 & 0.692 & 0.663 \\
\hline 2015 & 0.737 & 0.709 & 2015 & 0.649 & 0.711 & 2015 & 0.710 & 0.705 \\
\hline 2016 & 0.749 & 0.754 & 2016 & 0.791 & 0.774 & 2016 & 0.708 & 0.710 \\
\hline 2017 & 0.685 & 0.673 & 2017 & 0.699 & 0.677 & 2017 & 0.696 & 0.700 \\
\hline 2018 & 0.593 & 0.714 & 2018 & 0.689 & 0.707 & 2018 & 0.654 & 0.701 \\
\hline \multicolumn{3}{|l|}{ VMMC } & \multicolumn{3}{|l|}{ PEP } & \multicolumn{3}{|l|}{ BS } \\
\hline Year & $K=3$ & $K=4$ & Year & $K=3$ & $K=4$ & Year & $K=3$ & $K=4$ \\
\hline 2011 & a & a & 2011 & 0.704 & 0.679 & 2011 & a & a \\
\hline 2012 & 1.00 & b & 2012 & 0.593 & 0.605 & 2012 & 0.734 & 0.730 \\
\hline 2013 & 0.64 & 0.669 & 2013 & 0.639 & 0.629 & 2013 & 0.732 & 0.687 \\
\hline 2014 & 0.634 & 0.661 & 2014 & 0.675 & 0.667 & 2014 & 0.712 & 0.650 \\
\hline 2015 & 0.733 & 0.681 & 2015 & 0.682 & 0.673 & 2015 & 0.617 & 0.641 \\
\hline 2016 & 0.708 & 0.699 & 2016 & 0.696 & 0.665 & 2016 & 0.719 & 0.680 \\
\hline 2017 & 0.765 & 0.733 & 2017 & 0.621 & 0.611 & 2017 & 0.577 & 0.637 \\
\hline 2018 & 0.657 & 0.636 & 2018 & 0.650 & 0.673 & 2018 & 0.610 & 0.607 \\
\hline
\end{tabular}

a There are not enough valid cases to conduct the specified cluster analysis

b In the data, there is insufficient variation to honor the four clusters specified. The number of clusters is reduced to 3

to the CRT programmatic area. As such, Table 5 includes the average percentage for facility reporting completeness and timeliness for each cluster group in CRT for the number of facilities $(\mathrm{n})$ in a particular year.

Figure 4 consists of a graphical presentation of the proportion of facilities in each cluster group per year for CRT. Based on performance trends presented in Fig. 4, the proportion of best performing facilities accounted for $75.49 \%$ in 2016, which was a progressive increase from $5.65 \%$ in 2011. Nonetheless, in 2018 the proportion of best performing facilities accounted for $53.24 \%$, which was a progressive decrease from $75.49 \%$ in 2016 . On the other hand, the proportion of poor performing facilities accounted for $2.99 \%$ in 2016 , which was a progressive decrease from $71.75 \%$ in 2011. However, in 2018 the proportion of poor performing facilities accounted for $17.47 \%$, which was a progressive increase from $2.99 \%$ in 2016.

The proportion of average and outlier performing facilities varied in the different years with no steady trend. Nonetheless, for the latter years the proportion of average performing facilities accounted for $24.81 \%$ in 2018 , which was an increase from $7.06 \%$ in 2016 . On the other hand, proportion of outlier performers accounted for
$4.48 \%$ in 2018 , which was a progressive decrease from $14.46 \%$ in 2016.

In Table 6 and Fig. 5, we present the segmentation of facilities based on performance cluster groups according to the VMMC programmatic area. As such, Table 6 includes the average percentage for facility reporting completeness and timeliness for each cluster group in VMMC for the number of facilities (n) in a particular year.

Figure 5 consists of a graphical presentation of the proportion of facilities in each cluster group per year for VMMC. Based on performance trends presented in Fig. 5, the proportion of best performing facilities accounted for $54.35 \%$ in 2016, which was a progressive increase from $8.70 \%$ in 2013. Nonetheless, in 2018 the proportion of best performing facilities accounted for $17.31 \%$, which was a progressive decrease from $54.35 \%$ in 2016. On the other hand, the proportion of poor performing facilities accounted for $13.04 \%$ in 2016, which was a progressive decrease from $39.13 \% \%$ in 2013 . However, in 2017 and 2018 the proportion of poor performing facilities accounted for $21.88 \%$ and $21.15 \%$, which was a progressive increase from $13.04 \%$ in 2016.

The proportion of average and outlier performing facilities varied in the different years with no steady trend. 
Table 3 HIV testing and counselling (HTC)-health facility (n) segmentation based on performance clusters

\begin{tabular}{|c|c|c|c|c|c|c|c|c|c|c|c|c|}
\hline \multirow{2}{*}{$\begin{array}{l}\text { Year } \\
\text { Cluster group }\end{array}$} & \multicolumn{4}{|l|}{2011} & \multicolumn{8}{|c|}{2012} \\
\hline & \multirow{2}{*}{$\begin{array}{l}\text { Best } \\
\mathbf{n}=\mathbf{0}\end{array}$} & \multirow{2}{*}{$\begin{array}{l}\text { Average } \\
\mathbf{n}=177\end{array}$} & $\begin{array}{l}\text { Poor } \\
n=556\end{array}$ & Outlier $n=9$ & \multicolumn{2}{|c|}{ Best $n=1206$} & \multicolumn{2}{|c|}{$\begin{array}{l}\text { Average } \\
n=1301\end{array}$} & \multicolumn{2}{|c|}{$\begin{array}{l}\text { Poor } \\
n=794\end{array}$} & \multicolumn{2}{|c|}{ Outlier $n=528$} \\
\hline $\begin{array}{l}\text { MOH 731-1 } \\
\text { HTC com- } \\
\text { pleteness }\end{array}$ & & & 13.07 & 91.67 & \multicolumn{2}{|c|}{90.08} & \multicolumn{2}{|c|}{55.30} & \multicolumn{2}{|c|}{25.68} & \multicolumn{2}{|l|}{86.75} \\
\hline $\begin{array}{l}\text { MOH 731-1 } \\
\text { HTC timeli- } \\
\text { ness }\end{array}$ & 0.00 & 16.63 & 2.91 & 21.30 & \multicolumn{2}{|c|}{80.47} & \multicolumn{2}{|c|}{45.65} & \multicolumn{2}{|c|}{16.11} & \multicolumn{2}{|l|}{46.17} \\
\hline Year & \multicolumn{4}{|l|}{2013} & \multicolumn{8}{|c|}{2014} \\
\hline Cluster group & Best $n=3219$ & $\begin{array}{l}\text { Average } \\
\mathrm{n}=806\end{array}$ & Poor $n=437$ & $\begin{array}{l}\text { Outlier } \\
n=427\end{array}$ & \multicolumn{2}{|c|}{ Best $n=3837$} & \multicolumn{2}{|c|}{$\begin{array}{l}\text { Average } \\
n=568\end{array}$} & \multicolumn{2}{|c|}{ Poor $n=297$} & \multicolumn{2}{|c|}{ Outlier $n=615$} \\
\hline $\begin{array}{c}\text { MOH 731-1 } \\
\text { HTC com- } \\
\text { pleteness }\end{array}$ & 96.73 & 68.77 & 32.96 & 89.86 & \multicolumn{2}{|c|}{98.18} & \multicolumn{2}{|c|}{73.07} & \multicolumn{2}{|c|}{33.75} & \multicolumn{2}{|c|}{95.94} \\
\hline $\begin{array}{l}\text { MOH 731-1 } \\
\text { HTC timeli- } \\
\text { ness }\end{array}$ & 89.55 & 57.33 & 21.63 & 43.00 & 92. & & \multicolumn{2}{|c|}{62.42} & 23.02 & & 54.06 & \\
\hline Year & 2015 & & & & & 2016 & & & & & & \\
\hline Cluster group & Best $n=3916$ & $\begin{array}{l}\text { Average } \\
n=1172\end{array}$ & Poor $n=296$ & Outlier $\mathrm{n}=$ & 282 & Best $n=43$ & & $\begin{array}{l}\text { Average } \\
n=362\end{array}$ & & Poor $n=$ & $=205$ & $\begin{array}{l}\text { Outlier } \\
n=1089\end{array}$ \\
\hline $\begin{array}{r}\text { MOH 731-1 HTC } \\
\text { completeness }\end{array}$ & 99.40 & 88.30 & 34.57 & 93.09 & & 99.34 & & 69.15 & & 31.47 & & 91.29 \\
\hline $\begin{array}{l}\mathrm{MOH} 731-1 \mathrm{HTC} \\
\text { timeliness }\end{array}$ & 96.33 & 71.71 & 27.45 & 33.45 & & 95.89 & & 51.07 & & 20.29 & & 74.04 \\
\hline Year & 2017 & & & & 201 & & & & & & & \\
\hline Cluster group & Best $n=3698$ & $\begin{array}{l}\text { Average } \\
n=1164\end{array}$ & Poor $n=338$ & $\begin{array}{l}\text { Outlier } \\
n=1143\end{array}$ & Bes & $\mathrm{t} n=3403$ & $\begin{array}{l}\text { Ave } \\
n=\end{array}$ & $\begin{array}{l}\text { age } \\
1334\end{array}$ & Poor & $n=899$ & $\begin{array}{l}\text { Outlie } \\
n=10\end{array}$ & \\
\hline $\begin{array}{l}\text { MOH 731-1 } \\
\text { HTC com- } \\
\text { pleteness }\end{array}$ & 97.98 & 64.47 & 32.69 & 94.20 & 88.4 & & 52.6 & & 26.87 & & 77.35 & \\
\hline $\begin{array}{l}\text { MOH 731-1 } \\
\text { HTC timeli- } \\
\text { ness }\end{array}$ & 93.92 & 57.04 & 23.59 & 64.33 & 86.9 & & 48.8 & & 22.98 & & 64.65 & \\
\hline
\end{tabular}

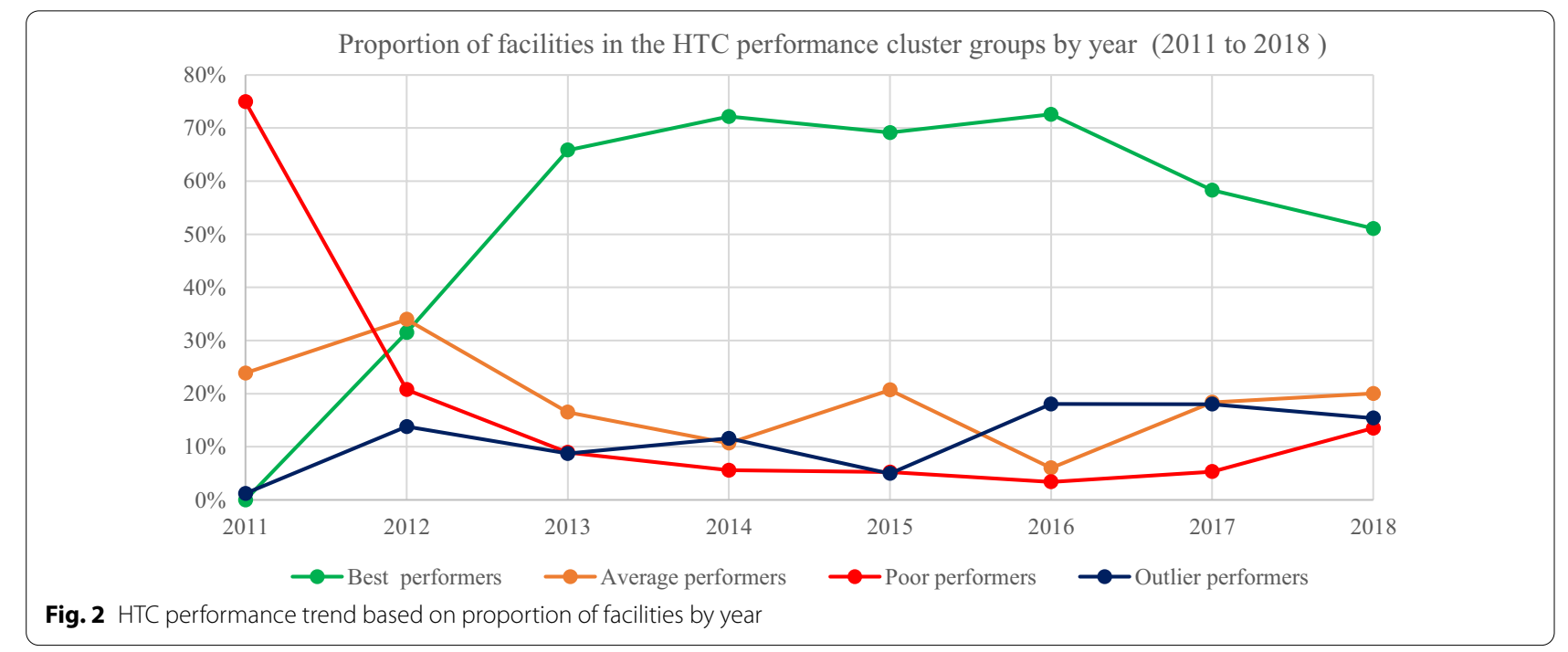


Table 4 Prevention of Mother to Child Transmission (PMTCT)—health facility (n) segmentation based on performance clusters

\begin{tabular}{|c|c|c|c|c|c|c|c|c|}
\hline \multirow{2}{*}{$\begin{array}{l}\text { Year } \\
\text { Cluster group }\end{array}$} & \multicolumn{4}{|l|}{2011} & \multicolumn{4}{|l|}{2012} \\
\hline & Best $n=132$ & Average $n=20$ & Poor $n=541$ & Outlier $n=9$ & Best $n=1052$ & $\begin{array}{l}\text { Average } \\
n=1230\end{array}$ & Poor $n=782$ & Outlier $n=508$ \\
\hline $\begin{array}{l}\text { MOH 731-2 } \\
\text { PMTCT com- } \\
\text { pleteness }\end{array}$ & 21.67 & 38.32 & 12.91 & 91.67 & 90.03 & 55.51 & 26.09 & 85.65 \\
\hline $\begin{array}{l}\text { MOH 731-2 } \\
\text { PMTCT timeli- } \\
\text { ness }\end{array}$ & 18.64 & 4.58 & 2.81 & 18.52 & 80.87 & 45.55 & 16.20 & 47.33 \\
\hline Year & \multicolumn{4}{|l|}{2013} & \multicolumn{4}{|l|}{2014} \\
\hline Cluster group & Best $n=2277$ & $\begin{array}{l}\text { Average } \\
n=1188\end{array}$ & Poor $n=527$ & Outlier $n=444$ & Best $n=2737$ & $\begin{array}{l}\text { Average } \\
n=1210\end{array}$ & Poor $n=277$ & Outlier $n=586$ \\
\hline $\begin{array}{l}\text { MOH 731-2 } \\
\text { PMTCT com- } \\
\text { pleteness }\end{array}$ & 97.73 & 84.02 & 37.19 & 85.98 & 98.61 & 89.43 & 37.03 & 96.26 \\
\hline $\begin{array}{l}\text { MOH 731-2 } \\
\text { PMTCT timeli- } \\
\text { ness }\end{array}$ & 92.11 & 63.53 & 26.11 & 29.70 & 92.31 & 59.29 & 24.02 & 14.54 \\
\hline Year & \multicolumn{4}{|l|}{2015} & \multicolumn{4}{|l|}{2016} \\
\hline Cluster group & Best $\mathrm{n}=3785$ & Average $\mathrm{n}=517$ & Poor $n=187$ & Outlier $n=625$ & Best $n=2732$ & $\begin{array}{l}\text { Average } \\
n=1156\end{array}$ & Poor $n=237$ & Outlier $n=194$ \\
\hline $\begin{array}{l}\text { MOH 731-2 } \\
\text { PMTCT com- } \\
\text { pleteness }\end{array}$ & 98.84 & 75.61 & 30.34 & 98.13 & 99.43 & 90.03 & 37.95 & 89.32 \\
\hline $\begin{array}{l}\text { MOH 731-2 } \\
\text { PMTCT timeli- } \\
\text { ness }\end{array}$ & 91.22 & 61.72 & 21.97 & 38.76 & 95.42 & 72.36 & 25.98 & 38.46 \\
\hline Year & \multicolumn{4}{|l|}{2017} & \multicolumn{4}{|l|}{2018} \\
\hline Cluster group & Best $n=3456$ & Average $n=944$ & Poor $n=348$ & Outlier $n=744$ & Best $n=2685$ & $\begin{array}{l}\text { Average } \\
n=1259\end{array}$ & Poor $n=832$ & Outlier $n=1018$ \\
\hline $\begin{array}{l}\text { MOH 731-2 } \\
\text { PMTCT com- } \\
\text { pleteness }\end{array}$ & 97.58 & 64.96 & 38.51 & 93.73 & 88.48 & 53.03 & 27.69 & 79.02 \\
\hline $\begin{array}{l}\text { MOH 731-2 } \\
\text { PMTCT timeli- } \\
\text { ness }\end{array}$ & 91.54 & 58.59 & 26.55 & 54.52 & 86.72 & 48.22 & 22.65 & 63.20 \\
\hline
\end{tabular}

Nonetheless, for the latter years, the proportion of average performing facilities accounted for $25.00 \%$ in 2018 , which was an increase from $15.63 \%$ in 2017 . On the other hand, proportion of outlier performers accounted for $36.54 \%$ in 2018 , which was a progressive increase from $10.87 \%$ in 2016.

In Table 7 and Fig. 6, we present the segmentation of facilities based on performance cluster groups according to the PEP programmatic area. As such, Table 7 includes the average percentage for facility reporting completeness and timeliness for each cluster group in PEP for the number of facilities $(n)$ in a particular year.
Figure 6 consists of a graphical presentation of the proportion of facilities in each cluster group per year for PEP. Based on performance trends presented in Fig. 6, the proportion of best performing facilities accounted for $66.76 \%$ in 2015 , which was a progressive increase from $2.99 \%$ in 2011. Nonetheless, in 2018 the proportion of best performing facilities accounted for $51.24 \%$, which was a decrease from $66.01 \%$ in 2017 . On the other hand, the proportion of poor performing facilities accounted for $3.91 \%$ in 2016, which was a progressive decrease from $17.76 \%$ in 2013. However, in 2018 the proportion of poor performing facilities accounted for $18.59 \%$, which was a progressive increase from $3.91 \%$ in 2016. 


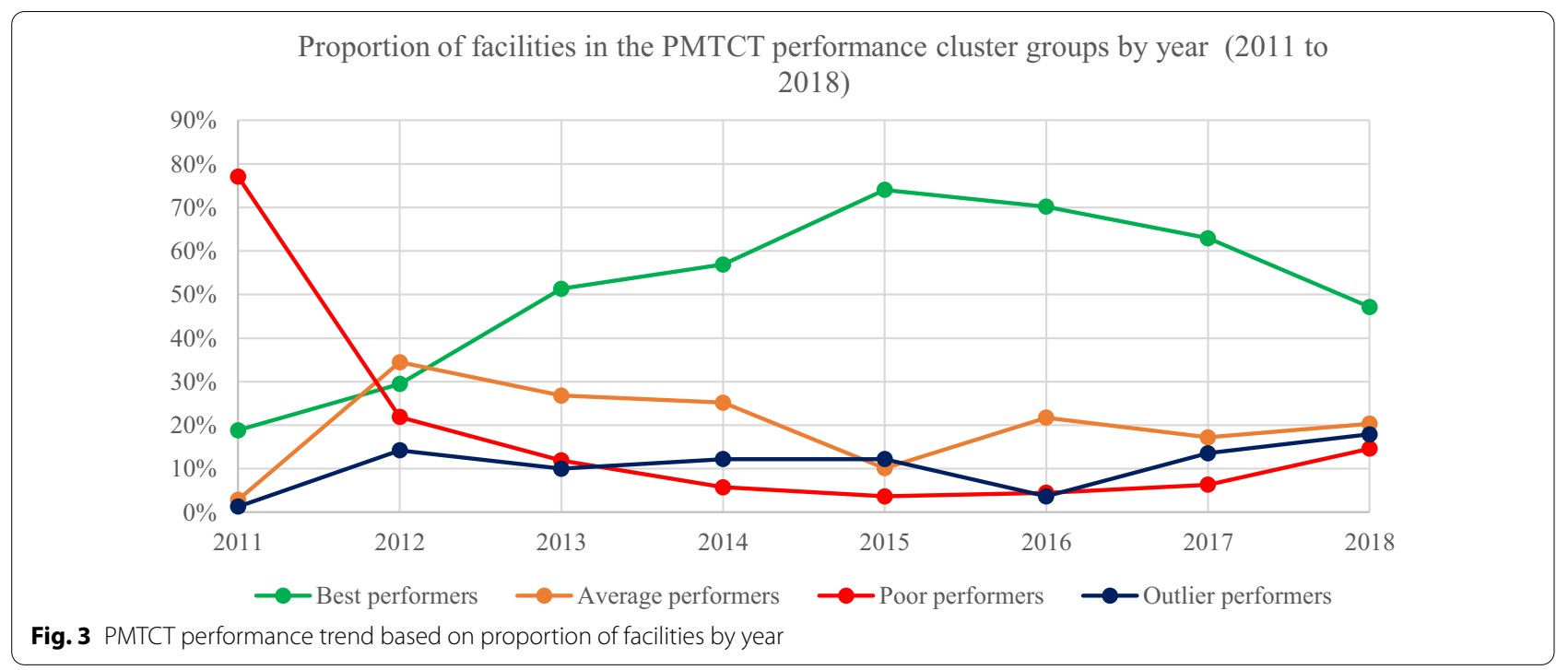

The proportion of average and outlier performing facilities varied in the different years with no steady trend. Nonetheless, for the latter years the proportion of average performing facilities accounted for $28.76 \%$ in 2018 , which was an increase from $17.09 \%$ in 2017 . On the other hand, proportion of outlier performers accounted for $1.41 \%$ in 2018 , which was a progressive decrease from $24.78 \%$ in 2016.

In Table 8 and Fig. 7, we present the segmentation of facilities based on performance cluster groups according to the BS programmatic area. As such, Table 8 includes the average percentage for facility reporting completeness and timeliness for each cluster group in BS for the number of facilities ( $\mathrm{n}$ ) in a particular year.

Figure 7 consists of a graphical presentation of the proportion of facilities in each cluster group per year for BS. Based on performance trends presented in Fig. 7, the proportion of best performing facilities accounted for $26.67 \%$ in 2015 and 2016, which was a decrease from $33.33 \%$ in 2014. Nonetheless, in 2018 the proportion of best performing facilities accounted for $15.38 \%$, which was a decrease from $32.00 \%$ in 2017 . On the other hand, the proportion of poor performing facilities accounted for $20.00 \%$ in 2015 and 2016, which was a progressive decrease from $43.48 \%$ in 2011. However, in 2017 the proportion of poor performing facilities accounted for $24.00 \%$, which was an increase from 2016. For the latter years, the proportion of average performing facilities accounted for $28.00 \%$ in 2017 and $38.46 \%$ in 2018 . On the other hand, proportion of outlier performers accounted for $16.00 \%$ in 2017 and $23.08 \%$ 2018. Nonetheless, there have been a general progressive decrease in facilities submitting BS indicators from 2013 to 2018.

\section{Scatter chart visualization of HTC performance clusters}

In this section, we present an interactive visual representation of performance cluster groups using scatter charts. As an illustrative example using performance reporting of the HTC programmatic area, Fig. 8 demonstrates the visualization of the average performance of facilities by county for the period 2011 to 2018. Each of the four performance cluster groups are represented using a similar color approach in Figs. 2, 3, 4, 5, 6 and 7. Each point contains the following attributes: name of county, number of facilities represented in that county, and the average completeness and timeliness for the facilities, which are displayed upon hovering the mouse on a point. For example, a green point may represent the average completeness and timeliness for the number of facilities in Nairobi county, which were in the best performing cluster in a particular year. This scenario is replicated for other counties and performance clusters. It is worth noting that facilities represented in each point are of varying characteristics such as type (hospital, health center), and ownership (private, public), hence are clustered based on performance. As such, the points in the scatter chart visualization provide a clear illustration of the four performance cluster groups and their behavior over time. For instance, the initial year of reporting shows only few clusters. Nonetheless, as reporting increases with time, more clusters develop.

Moreover, the outlier performance cluster has shown some improvement in performance as demonstrated with the left movement in the chart over time. The best performing cluster (green) also demonstrates a similar observation with the most improvement in 2016. The illustration in Fig. 2 further shows the proportion of best performing facilities being higher in 2016 . 
Table 5 Care and Treatment (CRT) — health facility (n) segmentation based on performance clusters

\begin{tabular}{|c|c|c|c|c|c|c|c|c|}
\hline \multirow{2}{*}{$\begin{array}{l}\text { Year } \\
\text { Cluster group }\end{array}$} & \multicolumn{4}{|l|}{2011} & \multicolumn{4}{|l|}{2012} \\
\hline & Best $n=20$ & $\begin{array}{l}\text { Average } \\
n=76\end{array}$ & Poor $n=254$ & Outlier $n=4$ & Best $n=634$ & $\begin{array}{l}\text { Average } \\
n=662\end{array}$ & Poor $n=430$ & Outlier $n=98$ \\
\hline $\begin{array}{l}\text { MOH 731-3 } \\
\text { care and } \\
\text { treatment } \\
\text { complete- } \\
\text { ness }\end{array}$ & 42.50 & 21.61 & 12.49 & 93.75 & 90.00 & 57.90 & 24.69 & 84.61 \\
\hline $\begin{array}{l}\text { MOH 731-3 } \\
\text { care and } \\
\text { treatment } \\
\text { timeliness }\end{array}$ & 2.09 & 17.79 & 2.70 & 22.93 & 76.54 & 46.74 & 15.29 & 22.81 \\
\hline Year & \multicolumn{4}{|l|}{2013} & \multicolumn{4}{|l|}{2014} \\
\hline Cluster group & Best $n=1063$ & $\begin{array}{l}\text { Average } \\
n=587\end{array}$ & Poor $n=217$ & $\begin{array}{l}\text { Outlier } \\
n=219\end{array}$ & Best $n=1407$ & $\begin{array}{l}\text { Average } \\
n=554\end{array}$ & Poor $n=204$ & Outlier $n=236$ \\
\hline $\begin{array}{l}\text { MOH 731-3 } \\
\text { care and } \\
\text { treatment } \\
\text { complete- } \\
\text { ness }\end{array}$ & 97.67 & 81.29 & 31.24 & 90.05 & 98.67 & 87.86 & 34.51 & 94.53 \\
\hline $\begin{array}{l}\text { MOH 731-3 } \\
\text { care and } \\
\text { treatment } \\
\text { timeliness }\end{array}$ & 90.81 & 59.82 & 19.79 & 24.03 & 92.01 & 62.55 & 27.03 & 24.65 \\
\hline Year & \multicolumn{4}{|l|}{2015} & \multicolumn{4}{|l|}{2016} \\
\hline Cluster group & Best $n=1647$ & $\begin{array}{l}\text { Average } \\
n=607\end{array}$ & Poor $n=132$ & $\begin{array}{l}\text { Outlier } \\
n=227\end{array}$ & Best $n=2171$ & $\begin{array}{l}\text { Average } \\
n=203\end{array}$ & Poor $n=86$ & Outlier $n=416$ \\
\hline $\begin{array}{l}\text { MOH 731-3 } \\
\text { care and } \\
\text { treatment } \\
\text { complete- } \\
\text { ness }\end{array}$ & 99.00 & 93.63 & 35.73 & 93.96 & 99.09 & 76.65 & 27.22 & 97.21 \\
\hline $\begin{array}{l}\mathrm{MOH} 731-3 \\
\text { care and } \\
\text { treatment } \\
\text { timeliness }\end{array}$ & 94.71 & 66.06 & 23.13 & 25.27 & 91.13 & 59.43 & 16.15 & 38.87 \\
\hline Year & \multicolumn{4}{|l|}{2017} & \multicolumn{4}{|l|}{2018} \\
\hline Cluster group & Best $n=1837$ & $\begin{array}{l}\text { Average } \\
n=750\end{array}$ & Poor $n=264$ & $\begin{array}{l}\text { Outlier } \\
n=241\end{array}$ & Best $n=1676$ & $\begin{array}{l}\text { Average } \\
\mathrm{n}=781\end{array}$ & Poor $n=550$ & Outlier $n=141$ \\
\hline $\begin{array}{l}\text { MOH 731-3 } \\
\text { care and } \\
\text { treatment } \\
\text { complete- } \\
\text { ness }\end{array}$ & 98.82 & 92.41 & 43.10 & 95.74 & 86.94 & 55.13 & 26.68 & 71.65 \\
\hline $\begin{array}{l}\text { MOH 731-3 } \\
\text { care and } \\
\text { treatment } \\
\text { timeliness }\end{array}$ & 94.22 & 65.41 & 32.70 & 27.61 & 81.75 & 50.71 & 23.26 & 21.37 \\
\hline
\end{tabular}

Further still, the average facility reporting completeness and timeliness among the average performance cluster group (orange), seemed to have improved in 2015 compared with previous and subsequent years, based on the upward shift in the chart.

\section{Discussion}

The results of our study demonstrate how k-means clustering and interactive cluster-based visualization can be used in identifying patterns and categories within national-level HIV reporting systems, uncovering previously unrecognized patterns. The four categories 
Proportion of facilities in the CRT performance cluster groups by year (2011 to 2018 )

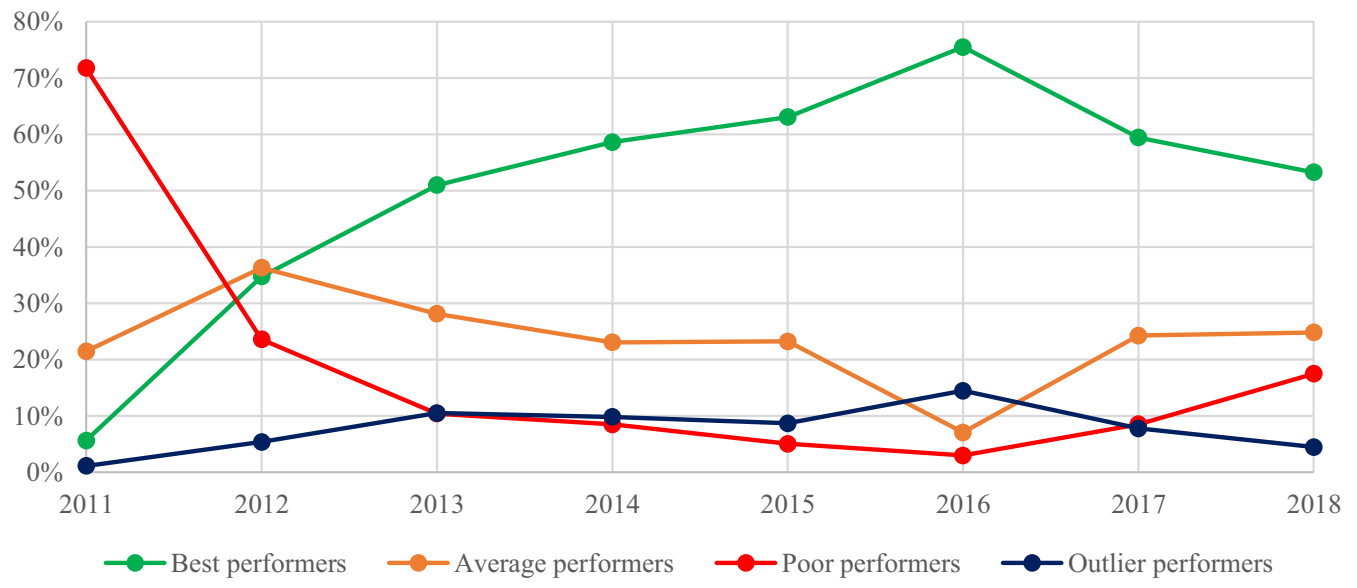

Fig. 4 CRT performance trend based on proportion of facilities by year

Table 6 Voluntary Medical Male Circumcision (VMMC)-health facility (n) segmentation based on performance clusters

\begin{tabular}{|c|c|c|c|c|c|c|c|c|c|}
\hline \multirow{2}{*}{$\begin{array}{l}\text { Year } \\
\text { Cluster group }\end{array}$} & \multicolumn{5}{|l|}{2012} & \multicolumn{4}{|l|}{2013} \\
\hline & Best $n=0$ & Average $n=2$ & Poor $n=2$ & \multicolumn{2}{|c|}{ Outlier $n=2$} & Best $n=2$ & Average $n=7$ & Poor $n=4$ & Outlier $n=5$ \\
\hline $\begin{array}{l}\text { MOH 731-4 VMMC com- } \\
\text { pleteness }\end{array}$ & 0.00 & 17.00 & 8.00 & \multicolumn{2}{|c|}{8.00} & 54.50 & 35.57 & 13.89 & 51.80 \\
\hline $\begin{array}{l}\mathrm{MOH} 731-4 \mathrm{VMMC} \\
\text { timeliness }\end{array}$ & 0.00 & 17.00 & 8.00 & \multicolumn{2}{|c|}{0.00} & 50.00 & 19.00 & 7.33 & 23.40 \\
\hline Year & \multicolumn{5}{|l|}{2014} & \multicolumn{4}{|l|}{2015} \\
\hline Cluster group & Best $n=7$ & Average $n=14$ & Poor $n=16$ & \multicolumn{2}{|c|}{ Outlier $n=5$} & Best $n=15$ & Average $n=7$ & Poor $n=7$ & Outlier $n=15$ \\
\hline $\begin{array}{l}\text { MOH 731-4 VMMC } \\
\text { completeness }\end{array}$ & 85.86 & 51.14 & 20.38 & \multicolumn{2}{|c|}{81.80} & 95.07 & 50.00 & 15.57 & 86.67 \\
\hline $\begin{array}{l}\text { MOH 731-4 VMMC } \\
\text { timeliness }\end{array}$ & 81.14 & 39.36 & 13.00 & \multicolumn{2}{|c|}{36.60} & 88.38 & 42.86 & 14.43 & 62.20 \\
\hline Year & \multicolumn{5}{|l|}{2016} & \multicolumn{4}{|l|}{2017} \\
\hline Cluster group & Best $n=25$ & Average $n=10$ & Poor $n=7$ & \multicolumn{2}{|c|}{ Outlier $n=4$} & Best $n=28$ & Average $n=10$ & Poor $n=14$ & Outlier $n=12$ \\
\hline $\begin{array}{l}\mathrm{MOH} 731-4 \mathrm{VMMC} \\
\text { completeness }\end{array}$ & 97.12 & 67.60 & 17.86 & \multicolumn{2}{|c|}{70.75} & 92.61 & 52.40 & 17.79 & 86.83 \\
\hline $\begin{array}{l}\text { MOH 731-4 VMMC } \\
\text { timeliness }\end{array}$ & 90.00 & 62.60 & 13.14 & \multicolumn{2}{|c|}{16.75} & 86.88 & 37.40 & 10.57 & 58.31 \\
\hline Year & 2018 & & & & & & & & \\
\hline Cluster group & Best $n=9$ & Average $n=13$ & 3 Poor $n=$ & & \multicolumn{2}{|c|}{ Outlier $n=19$} & & & \\
\hline $\begin{array}{l}\text { MOH 731-4 VMMC com- } \\
\text { pleteness }\end{array}$ & 85.73 & 43.94 & 19.09 & & 61.58 & & & & \\
\hline $\begin{array}{l}\text { MOH 731-4 VMMC timeli- } \\
\text { ness }\end{array}$ & 81.11 & 36.15 & 16.36 & & 55.26 & & & & \\
\hline
\end{tabular}

identified (best performers, average performers, poor performers, and outlier performers) reveal the variation in reporting performance among facilities with respect to year and programmatic area. Moreover, apart from the BS programmatic area, a distinct pattern observed in five of the other programmatic areas was that as the proportion of best performing facilities increased, the proportion of poor performing facilities decreased. In addition, the proportion of facilities in the best performing cluster was higher over time, compared to the proportion of 
Proportion of facilities in the VMMC performance cluster groups by year (2011 to 2018)

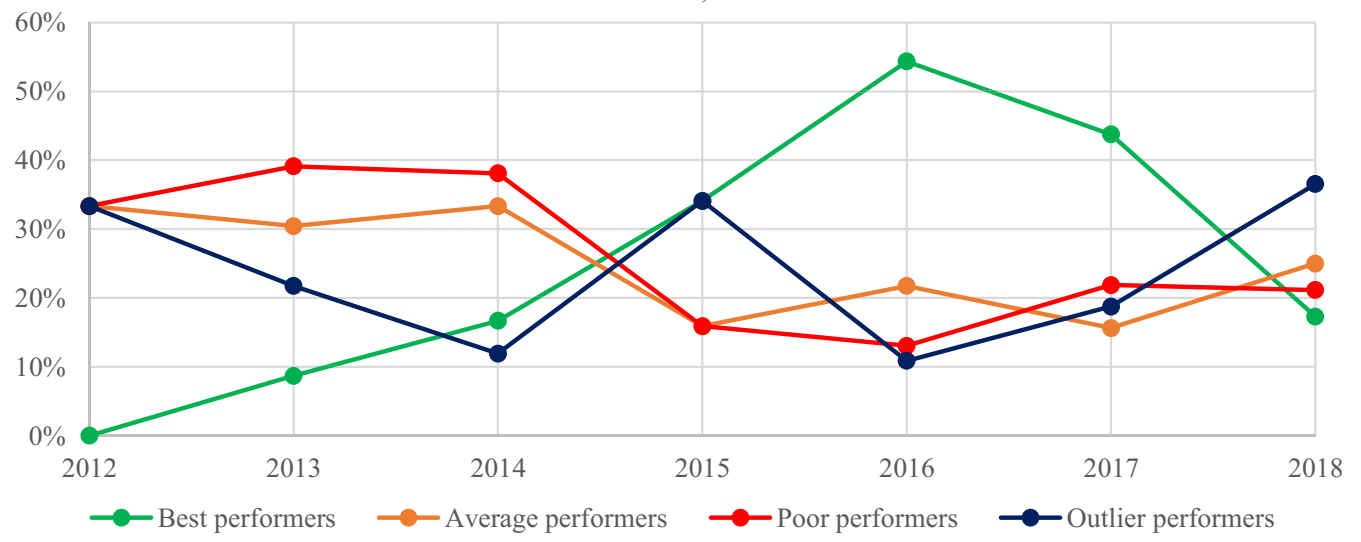

Fig. 5 VMMC performance trend based on proportion of facilities by year

facilities in the other performance clusters. These observations denote improvements in reporting over time within Kenya.

Factors that could explain these improvements in part include data quality improvement procedures done through progressive trainings of those collecting primary data and of health records information officers, provision of technical reporting support to facilities [16]. Other factors such as automation of indicator reporting by electronic medical records (EMRs) to the DHIS2, have the potential to improve routine reporting based on evidence from feasibility studies conducted [29]. With future prospects on automating indicator data reporting, cohort studies can be conducted to establish their impact based on facility reporting completeness and timeliness performance in DHIS2. Further, concerted efforts in improving routine performance of HMIS, touching on technical, behavioral and organizational domains can improve reporting in Kenya [30].

However, despite the observed improvements in performance, there was a decline in proportion of best performing facilities in different years (between 2016 and 2018), depending on the programmatic area. It is worth noting that Kenya experienced one of the longest health worker strike in the public-sector from 5 December 2016 to November 2017, lasting a total of 250 days [31]. The first phase (5 December to 14 March 2017), involved a doctors strike lasting 100 days [31]. Whereas the second phase (5 June to 1 November 2017) involved a nurses strike lasting 150 days [31]. As such, although there may have been other factors that contributed to the decline in proportion of best performing facilities, we suspect that these strikes might have also affected the reporting process. In addition, the decline in 2018 may be attributed to the introduction of new MOH731 summary reporting tools revised in 2018. As such, some facilities were still using the old tool while others had already began using the new tool, signifying the need to improve approaches during transition of reported data.

In overall, we observed that average percentage timeliness tended to be lower compared to average percentage completeness in all the four performance groups. This observation is reflected in other similar studies [12, 32]. Nonetheless, as much as this observation was common among the four performance groups, the outlier performance group specifically brings to light larger disparities between average completeness and timeliness. For instance, as presented in Table 3 for the year 2011, we see that average completeness is $91.67 \%$ and timeliness $21.30 \%$. Similar observations can be made for subsequent tables in the various programmatic areas.

Given that timeliness plays an important role in decision-making, there is a cause for concern when there is good effort in submitting of reports, with limitations on timeliness especially in the outlier performance group. As such, there is need for qualitative enquiries to investigate the large disparities in average percentage completeness and timeliness. This is because various factors could act as barriers or facilitators to health facilities ability to attaining and maintaining good completeness and timeliness reporting performance. These factors could be targeted by ministries of health in developing strategies to improve reporting performance of health facilities.

A limitation observed in the scatter chart was that the data points become densely packed in cases where they are many in a small area, hence making it difficult to identify the various points within a cluster. An example is best performers (Fig. 8), more so in 2016. Nonetheless, 
Table 7 Post-Exposure Prophylaxis (PEP)-health facility (n) segmentation based on performance clusters

\begin{tabular}{|c|c|c|c|c|c|c|c|c|}
\hline \multirow{2}{*}{$\begin{array}{l}\text { Year } \\
\text { Cluster groups }\end{array}$} & \multicolumn{4}{|l|}{2011} & \multicolumn{4}{|l|}{2012} \\
\hline & Best $n=0$ & Average $\mathrm{n}=2$ & Poor $n=63$ & Outlier $n=2$ & Best $n=173$ & $\begin{array}{l}\text { Average } \\
n=256\end{array}$ & Poor $n=328$ & Outlier $n=34$ \\
\hline $\begin{array}{l}\text { MOH } 731-5 \\
\text { post-exposure } \\
\text { prophylaxis } \\
\text { completeness }\end{array}$ & 0.00 & 54.20 & 13.48 & 95.85 & 84.98 & 54.24 & 23.56 & 89.71 \\
\hline $\begin{array}{l}\text { MOH } 731-5 \\
\text { post-exposure } \\
\text { prophylaxis } \\
\text { timeliness }\end{array}$ & 0.00 & 4.15 & 6.18 & 8.35 & 73.74 & 44.72 & 15.65 & 34.07 \\
\hline Year & \multicolumn{4}{|l|}{2013} & \multicolumn{4}{|l|}{2014} \\
\hline Cluster groups & Best $n=583$ & $\begin{array}{l}\text { Average } \\
n=281\end{array}$ & Poor $n=205$ & Outlier $n=85$ & Best $n=677$ & $\begin{array}{l}\text { Average } \\
n=221\end{array}$ & Poor $n=124$ & Outlier $n=281$ \\
\hline $\begin{array}{l}\text { MOH 731-5 } \\
\text { post-exposure } \\
\text { prophylaxis } \\
\text { completeness }\end{array}$ & 94.44 & 61.18 & 29.01 & 87.45 & 97.04 & 56.66 & 23.39 & 83.53 \\
\hline $\begin{array}{l}\text { MOH 731-5 } \\
\text { post-exposure } \\
\text { prophylaxis } \\
\text { timeliness }\end{array}$ & 88.01 & 51.75 & 20.00 & 41.74 & 93.14 & 40.20 & 17.24 & 63.91 \\
\hline Year & \multicolumn{4}{|l|}{2015} & \multicolumn{4}{|l|}{2016} \\
\hline Cluster groups & Best $n=954$ & $\begin{array}{l}\text { Average } \\
\mathrm{n}=305\end{array}$ & Poor $n=103$ & Outlier $n=67$ & Best $n=953$ & $\begin{array}{l}\text { Average } \\
n=161\end{array}$ & Poor $n=61$ & Outlier $n=387$ \\
\hline $\begin{array}{l}\text { MOH } 731-5 \\
\text { post-exposure } \\
\text { prophylaxis } \\
\text { completeness }\end{array}$ & 97.14 & 76.33 & 27.25 & 78.37 & 98.15 & 59.58 & 27.85 & 83.22 \\
\hline $\begin{array}{l}\text { MOH } 731-5 \\
\text { post-exposure } \\
\text { prophylaxis } \\
\text { timeliness }\end{array}$ & 93.05 & 62.86 & 22.34 & 29.24 & 95.37 & 46.37 & 22.83 & 70.99 \\
\hline Year & \multicolumn{4}{|l|}{2017} & \multicolumn{4}{|l|}{2018} \\
\hline Cluster groups & Best $n=1031$ & $\begin{array}{l}\text { Average } \\
n=267\end{array}$ & Poor $n=137$ & Outlier $n=127$ & Best $\mathrm{n}=725$ & $\begin{array}{l}\text { Average } \\
n=407\end{array}$ & Poor $n=263$ & Outlier $n=20$ \\
\hline $\begin{array}{l}\text { MOH 731-5 } \\
\text { post-exposure } \\
\text { prophylaxis } \\
\text { completeness }\end{array}$ & 95.73 & 66.51 & 38.29 & 90.02 & 85.04 & 54.06 & 24.07 & 80.50 \\
\hline $\begin{array}{l}\text { MOH 731-5 } \\
\text { post-exposure } \\
\text { prophylaxis } \\
\text { timeliness }\end{array}$ & 91.35 & 59.21 & 28.23 & 54.50 & 82.38 & 49.99 & 20.32 & 36.46 \\
\hline
\end{tabular}

interactive components (mouse hovering and filtering) incorporated within the scatter chart facilitate access to detailed information. As such, this allows for closer examination of various elements within the data set such as performance in individual counties and number of facilities within a county for a particular performance cluster. This also enables identifying areas that warrant further investigation in their performance, which contributes to informed decision-making. The interactive approach was also used based on the need to visualize various facets of data simultaneously, which can be a challenge [33].

Incorporation of these analyses as well as visualizations to run in real time within aggregate-level HMIS, have the potential to allow monitoring and timely responsiveness to performance changes. Moreover, off shelf software 


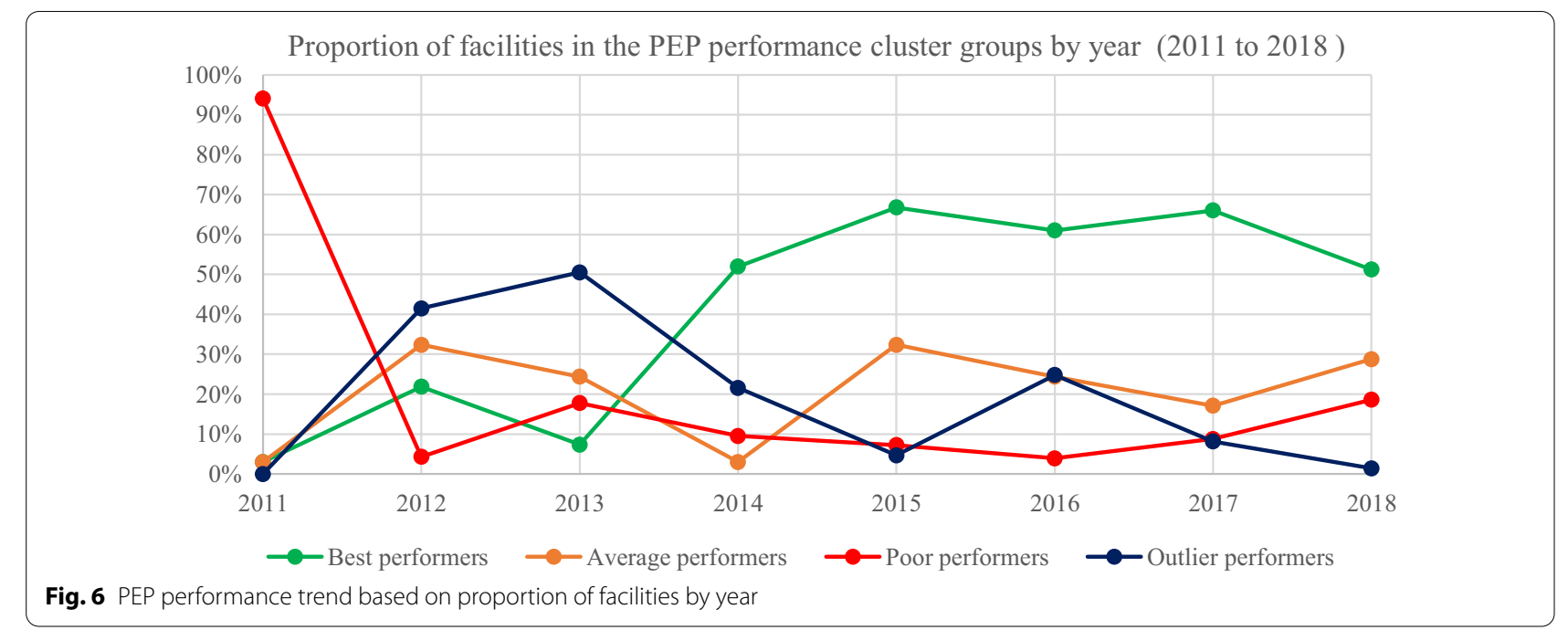

Table 8 Blood safety (BS)—health facility segmentation based on performance clusters

\begin{tabular}{|c|c|c|c|c|c|c|c|c|}
\hline \multirow{2}{*}{$\begin{array}{l}\text { Year } \\
\text { Cluster groups }\end{array}$} & \multicolumn{4}{|l|}{2012} & \multicolumn{4}{|l|}{2013} \\
\hline & Best $n=3$ & Average $n=8$ & Poor $n=10$ & Outlier $n=2$ & Best $n=8$ & Average $n=8$ & Poor $n=11$ & Outlier $n=12$ \\
\hline $\begin{array}{l}\text { MOH 731- } 6 \text { blood safety } \\
\text { completeness }\end{array}$ & 69.67 & 43.75 & 18.30 & 100.00 & 94.88 & 37.50 & 15.82 & 75.75 \\
\hline $\begin{array}{l}\mathrm{MOH} 731-6 \text { blood safety } \\
\text { timeliness }\end{array}$ & 67.00 & 35.25 & 14.23 & 54.00 & 91.50 & 30.13 & 8.18 & 57.00 \\
\hline Year & \multicolumn{4}{|l|}{2014} & \multicolumn{4}{|l|}{2015} \\
\hline Cluster groups & Best $n=11$ & Average $n=10$ & Poor $n=9$ & Outlier $n=3$ & Best $n=8$ & Average $n=14$ & Poor $n=6$ & Outlier $n=2$ \\
\hline $\begin{array}{l}\text { MOH 731- } 6 \text { blood safety } \\
\text { completeness }\end{array}$ & 95.55 & 67.60 & 47.33 & 97.33 & 87.38 & 62.43 & 22.17 & 58.00 \\
\hline $\begin{array}{l}\text { MOH } 731-6 \text { blood safety } \\
\text { timeliness }\end{array}$ & 87.95 & 62.50 & 40.33 & 22.33 & 81.25 & 45.86 & 15.17 & 8.50 \\
\hline Year & \multicolumn{4}{|l|}{2016} & \multicolumn{4}{|l|}{2017} \\
\hline Cluster groups & Best $n=8$ & Average $n=9$ & Poor $n=6$ & Outlier $n=7$ & Best $n=8$ & Average $n=7$ & Poor $n=6$ & Outlier $n=4$ \\
\hline $\begin{array}{l}\text { MOH 731-6 blood safety } \\
\text { completeness }\end{array}$ & 94.88 & 69.56 & 47.33 & 27.14 & 83.25 & 56.00 & 26.33 & 79.25 \\
\hline $\begin{array}{l}\text { MOH 731- } 6 \text { blood safety } \\
\text { timeliness }\end{array}$ & 92.79 & 62.00 & 40.33 & 17.86 & 78.13 & 54.86 & 22.33 & 41.50 \\
\hline Year & \multicolumn{4}{|l|}{2018} & & & & \\
\hline Cluster groups & Best $n=2$ & Average $n=5$ & Poor $n=3$ & \multicolumn{2}{|c|}{ Outlier $n=3$} & & & \\
\hline $\begin{array}{l}\text { MOH 731-6 blood safety } \\
\text { completeness }\end{array}$ & 85.00 & 54.00 & 26.67 & 66.67 & & & & \\
\hline $\begin{array}{l}\text { MOH 731- } 6 \text { blood safety } \\
\text { timeliness }\end{array}$ & 75.00 & 34.00 & 26.67 & 53.33 & & & & \\
\hline
\end{tabular}




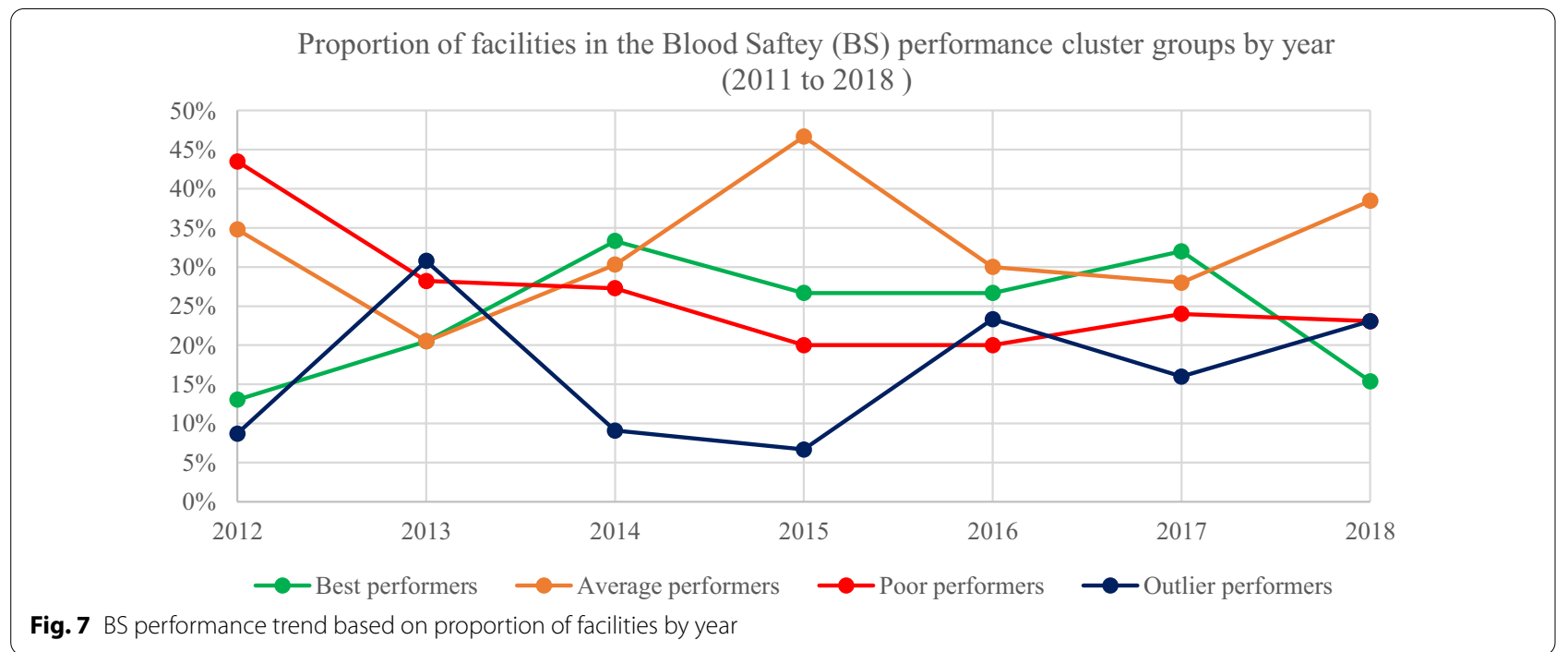

such as Tableau [27], which provide basic modules for free usage can be leveraged as a cost effective alternative for representing and sharing analysis for routinely collected data that has been extracted from large data systems.

The scope of the study can be relevant for many countries dealing with HIV reporting in aggregate-level HMIS. However, the limitation in this study is that data have been collected and analyzed for one country only. Nonetheless, the indicators used (completeness and timeliness) could also be relevant in other contexts. Further, the findings only reflect trends and associations, and do not explain causality. Investigations, including use of qualitative approaches, are needed to definitively determine causes of the observed trends and variations. While we only looked at clustering based on performance, we recognize that performance can be associated with several other factors including facility ownership (private vs public), facility type and level, (for example hospital, dispensary), presence or absence of electronic reporting systems, geographical location and infrastructure availability, among others.

One of the future aims will be to determine factors influencing movement of facilities between clusters with special attention to factors associated with decrease in performance.

\section{Conclusions}

K-means clustering and interactive cluster-based visualization was applied to identify patterns of performance in terms of completeness and timeliness of facility reporting in six HIV programmatic areas. This resulted to four clusters: best performers, average performers, poor performers, and outlier performers, depending on average percentage of completeness and timeliness. The identified clusters revealed general improvements in reporting performance in the various reporting areas over time, but with most noticeable decrease in some programmatic areas between 2016 and 2018. This signifies the need for continuous performance monitoring with possible integration of machine learning and visualization approaches into national HIV reporting systems.

As future work, we will also work with the relevant decision-makers in the study country to incorporate the demonstrated machine learning and visualization approaches for use in automatic and continuous assessment of reporting performance within Kenya. 
Gesicho et al. BMC Med Inform Decis Max

(2021) 21:6

Page 16 of 18

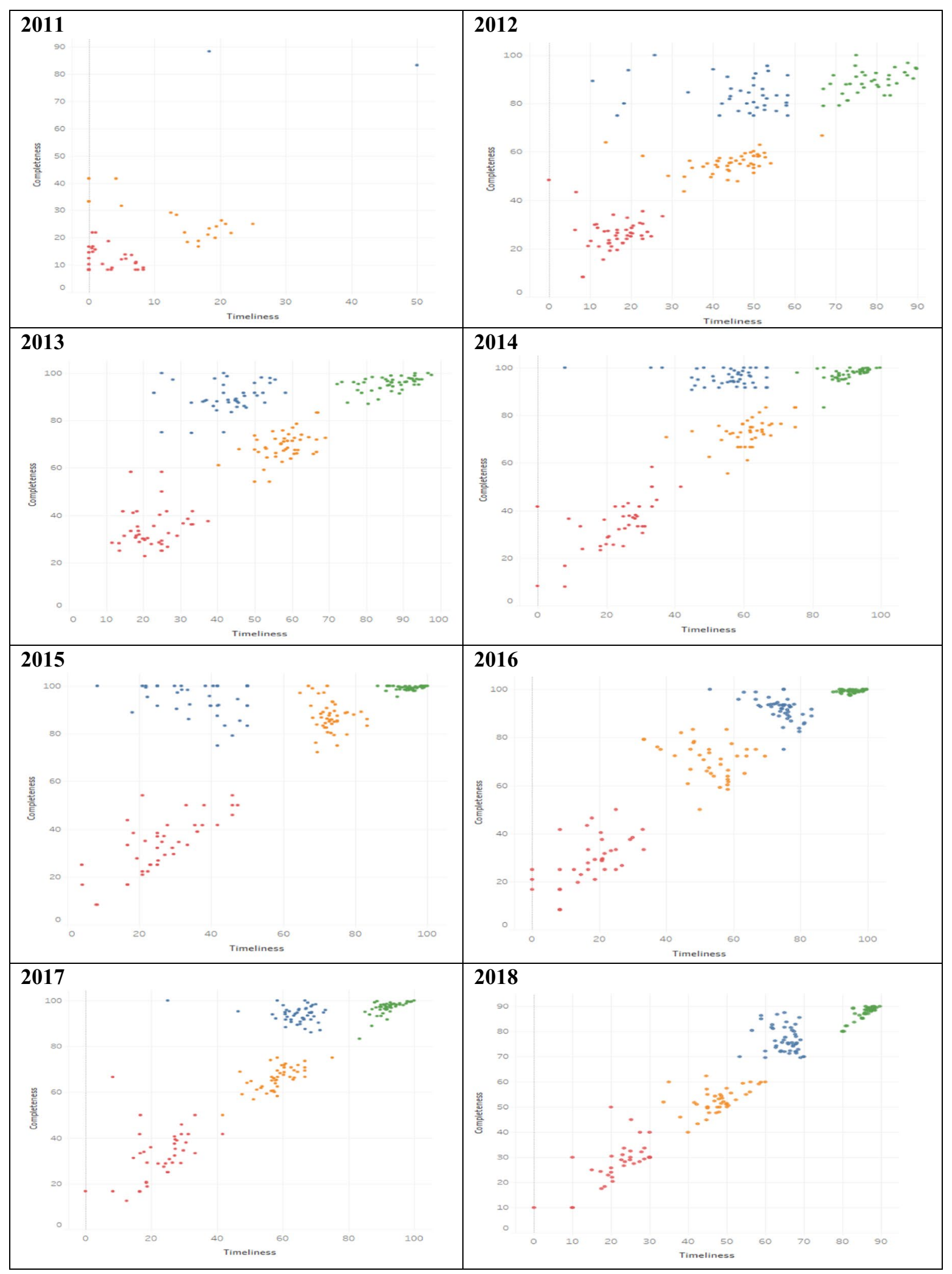

Fig. 8 Cluster visualization of facility performance by county illustration for HIV Testing and Counselling 


\section{Abbreviations}

ART: Antiretroviral therapy; BS: Blood Safety; CRT: Care and Treatment; DHIS2: District Health Information System Version 2; EMRs: Electronic Medical Record System; HTC: HIV Testing and Counselling; HIV: Human Immunodeficiency Virus; HMIS: Health Information Management Systems; LMICs: Low-middleincome countries; M\&E: Monitoring and Evaluation; $\mathrm{MoH}$ : Ministry of Health; PEP: Post-Exposure Prophylaxis; PMTCT: Prevention of Mother to Child Transmission; VMMC: Voluntary Medical Male Circumcision.

\section{Acknowledgements}

Not applicable.

\section{Authors' contributions}

$M G, A B$, and $M W$ designed the study. $A B$ and $M W$ supervised the study. $M G$ and $A B$ analyzed the data. All authors discussed the results, reviewed, and approved the final manuscript. MG wrote the final manuscript. All authors read and approved the final manuscript.

\section{Funding}

This work was supported in part by the NORHED program (Norad: Project QZA-0484). The content is solely the responsibility of the authors and does not represent the official views of the Norwegian Agency for Development Cooperation.

\section{Availability of data and materials}

The data sets generated during the current study are available in the national District Health Information Software 2 online database, https://hiskenya.org/.

\section{Ethics approval and consent to participate}

Ethical approval for this study was obtained from the Institutional Review and Ethics Committee (IREC) Moi University/Moi Teaching and Referral Hospital (Reference: IREC/2019/78)

\section{Consent for publication}

Not applicable.

\section{Competing interests}

The authors declare that they have no competing interests.

\section{Disclaimer}

The findings and conclusions in this report are those of the authors and do not represent the official position of the Ministry of Health in Kenya.

\section{Author details}

${ }^{1}$ Department of Information Science and Media Studies, University of Bergen, Bergen, Norway. ${ }^{2}$ Vanderbilt University Medical Center, Nashville, USA.

${ }^{3}$ Department of Biomedical Engineering, Linköping University, Linköping,

Sweden. ${ }^{4}$ Institute of Biomedical Informatics, Moi University, Eldoret, Kenya.

\section{Received: 5 August 2020 Accepted: 8 December 2020}

Published online: 06 January 2021

\section{References}

1. Global HIV and AIDS statistics - 2020 fact sheet | UNAIDS. https://www. unaids.org/en/resources/fact-sheet. Accessed 14 July 2020.

2. UNAIDS. Towards universal access. In: UNAIDS Annual Report. 2009. http://www.unaids.org/en/KnowledgeCentre/Resources/Publications/ default.asp. Accessed 14 July 2020.

3. Mbondo M, Scherer J, Aluoch GO, Sundsmo A, Mwaura N. Organizational HIV monitoring and evaluation capacity rapid needs assessment: the case of Kenya. Pan Afr Med J. 2013;14:1-7.

4. Porter LE, Bouey PD, Curtis S, Hochgesang M, Idele P, Jefferson B, et al. Beyond indicators. JAIDS J Acquir Immune Defic Syndr. 2012;60:S120-6.

5. Ekouevi DK, Karcher S, Coffie PA. Strengthening health systems through HIV monitoring and evaluation in Sub-Saharan Africa. Curr Opin HIV AIDS. 2011:6:245-50.
6. Saito S, Howard AA, Chege D, Ellman TM, Ahoua L, Elul B, et al. Monitoring quality at scale: implementing quality assurance in a diverse, multicountry HIV program. AIDS. 2015;29:S129-36.

7. Dehnavieh R, Haghdoost AA, Khosravi A, Hoseinabadi F, Rahimi H, Poursheikhali A, et al. The District Health Information System (DHIS2): a literature review and meta-synthesis of its strengths and operational challenges based on the experiences of 11 countries. Health Inf Manag. 2019;48:62-75

8. Manya A, Nielsen P. Reporting practices and data quality in health information systems in developing countries: an exploratory case study in Kenya. J Health Inform Dev Ctries. 2016;10:114-26.

9. WHO. Data Quality Review (DQR) Toolkit. WHO. In :World Health Organization; 2019. http://who.int/healthinfo/tools_data_analysis/en/. Accessed 5 Mar 2020.

10. Bhattacharya AA, Umar N, Audu A, Allen E, Schellenberg JRM, Marchant T. Quality of routine facility data for monitoring priority maternal and newborn indicators in DHIS2: a case study from Gombe State, Nigeria. PLOS ONE J. 2019;14:e0211265.

11. Githinji S, Oyando R, Malinga J, Ejersa W, Soti D, Rono J, et al. Completeness of malaria indicator data reporting via the District Health Information Software 2 in Kenya, 2011-2015. BMC Malar J. 2017;16:1-11.

12. Adokiya MN, Awoonor-Williams JK, Beiersmann C, Müller O. Evaluation of the reporting completeness and timeliness of the integrated disease surveillance and response system in northern Ghana. Ghana Med J. 2016:50:3-8.

13. Kiberu VM, Matovu JK, Makumbi F, Kyozira C, Mukooyo E, Wanyenze RK. Strengthening district-based health reporting through the district health management information software system: the Ugandan experience. BMC Med Inform Decis Mak. 2014;14:40.

14. Nisingizwe MP, lyer HS, Gashayija M, Hirschhorn LR, Amoroso C, Wilson R, et al. Toward utilization of data for program management and evaluation: quality assessment of five years of health management information system data in Rwanda. Glob Health Action. 2014;7:25829.

15. Muga R, Kizito P, Mbayah MM, Gakuruh T. Overview of the health system in Kenya. In: Kenya Service provision assessment survey 2004; 1999, p. $13-24$.

16. Manya A, Braa J, Øverland L, Titlestad O, Mumo J, Nzioka C. National roll out of District Health Information Software (DHIS 2) in Kenya, 2011-central server and cloud based infrastructure. IST-Africa. 2012;2012:1-9.

17. Karuri J, Waiganjo P, Orwa D, Manya A. DHIS2: the tool to improve health data demand and use in Kenya. J Health Inform Dev Ctries. 2014;8:38-60.

18. DHIS2: DHIS2 overview. https://www.dhis2.org/overview. Accessed 28 Sep 2020

19. DHIS2: SDHIS2 in action. https://www.dhis2.org/in-action. Accessed 28 Sep 2020.

20. Gesicho MB, Were MC, Babic A. Data cleaning process for HIV-indicator data extracted from DHIS2 national reporting system: a case study of Kenya. BMC Med Inform Decis Mak. 2020;20:293.

21. Jain AK. Data clustering: 50 years beyond K-means. Pattern Recognit Lett. 2010;31:651-66.

22. Everitt BS, Landau S, Leese M, Stahl D. Cluster analysis. 5th ed. Chichester: Wiley; 2011.

23. Rousseeuw PJ. Silhouettes: a graphical aid to the interpretation and validation of cluster analysis. J Comput Appl Math. 1987;20:53-65.

24. Kaufman $L$, Rousseeuw PJ. Finding groups in data, an introduction to cluster analysis. Hoboken: Wiley; 1990.

25. Pham DT, Dimov SS, Nguyen CD. Selection of K in K-means clustering. Proc Inst Mech Eng Part C J Mech Eng Sci. 2005;219:103-19.

26. Thinsungnoen T, Kaoungku N, Durongdumronchai P, Kerdprasop K, Kerdprasop N. The clustering validity with silhouette and sum of squared errors. In: International conference on industrial application engineering; 2015, p. 44-51.

27. Murray D, Chabot C. Tableau your data!: fast and easy visual analysis with tableau software. Hoboken: Wiley; 2013. p. 528

28. Corp IBM. IBM SPSS statistics for windows version 25. Armonk: IBM Corp; 2017.

29. Kariuki JM, Manders E-J, Richards J, Oluoch T, Kimanga D, Wanyee S, et al. Automating indicator data reporting from health facility EMR to a 
national aggregate data system in Kenya: an interoperability field-test using OpenMRS and DHIS2. Online J Public Health Inform. 2016;8:e188.

30. Aqil A, Lippeveld T, Hozumi D. PRISM framework: a paradigm shift for designing, strengthening and evaluating routine health information systems. Health Policy Plan. 2009;24:217-28.

31. Irimu G, Ogero M, Mbevi G, Kariuki C, Gathara D, Akech S, et al. Tackling health professionals'strikes: an essential part of health system strengthening in Kenya. BMJ Global Health. 2018;3:1136.

32. Joseph Wu T-S, Kagoli M, Kaasbøll JJ, Bjune GA. Integrated Disease

Surveillance and Response (IDSR) in Malawi: implementation gaps and challenges for timely alert. PLOS ONE. 2018;13:e200858.
33. Ola O, Sedig K. Beyond simple charts: design of visualizations for big health data. Online J Public Health Inform. 2016;8:e195.

\section{Publisher's Note}

Springer Nature remains neutral with regard to jurisdictional claims in published maps and institutional affiliations.
Ready to submit your research? Choose BMC and benefit from:

- fast, convenient online submission

- thorough peer review by experienced researchers in your field

- rapid publication on acceptance

- support for research data, including large and complex data types

- gold Open Access which fosters wider collaboration and increased citations

- maximum visibility for your research: over $100 \mathrm{M}$ website views per year

At BMC, research is always in progress.

Learn more biomedcentral.com/submissions 